\title{
Schwann cells promote the capability of neural stem cells to differentiate into neurons and secret neurotrophic factors
}

\author{
ZIWEI YU*, YONGZHI MEN* ${ }^{*}$ and PIN DONG \\ Department of Otolaryngology, Shanghai General Hospital, \\ Shanghai Jiao Tong University School of Medicine, Shanghai 200080, P.R. China
}

Received July 23, 2015; Accepted January 20, 2017

DOI: $10.3892 /$ etm.2017.4183

\begin{abstract}
The present study investigated whether co-culturing Schwann cells (SCs) with neural stem cells (NSCs) improves viability, direction of differentiation and secretion of brain-derived neurotrophic factor (BDNF) and glial cell-derived neurotrophic factor (GDNF) in NSCs. The three groups assessed were as follows: SCs, NSCs, and a co-culture of SCs and NSCs. Cellular morphological changes were observed under an inverted phase contrast microscope and quantified. Cells were identified by immunofluorescence staining: S100 for SCs, Nestin for NSCs, microtubule associated protein (Map) 2 and NeuN for neurons and glial fibrillary acidic protein for astrocytes. Cell viability was evaluated by MTT assay. Secretion of BDNF and GDNF was quantified; mRNA expression was quantified by reverse transcription-quantitative polymerase chain reaction. The majority of NSCs in the co-cultured group differentiated into neurons. The cell survival rate of the co-culture group was significantly higher than the other groups on days 3,5 and $10(\mathrm{P}<0.01)$. The secretion of BDNF in the co-culture group was significantly higher than NSCs on days 3, 5 and $7(\mathrm{P}<0.05)$, while the amount of GDNF in co-culture was significantly higher than both NSCs and SCs on day $1(\mathrm{P}<0.05)$. BDNF and GDNF gene expression in the co-culture group was significantly higher than SCs $(\mathrm{P}<0.01)$. Gene expression of Map2 in co-culture group was also significantly higher than both NSC and SC groups $(\mathrm{P}<0.01)$. Therefore, co-cultured SCs and NSCs promote differentiation of NSCs into neurons and secrete higher levels of neurotropic factors including BDNF and GDNF.
\end{abstract}

Correspondence to: Professor Pin Dong, Department of Otolaryngology, Shanghai General Hospital, Shanghai Jiao Tong University School of Medicine, 100 Haining Road, Building 2, 9th Floor, Shanghai 200080, P.R. China

E-mail: dongpin64@aliyun.com

*Contributed equally

Key words: neural stem cells, schwann cells, co-culture, neurotropic factors

\section{Introduction}

Peripheral nerve injury is a common cause of nerve function loss and this damage leads to severe disability, which is often permanent. Effective reparation of the nerve stump is a huge challenge for surgeons. Currently, autologous nerve grafting remains the gold standard for peripheral nerve repair (1). However, disadvantages, including limited donor site, secondary damage, sensory loss and trauma neuroma formation, remain (2). The limitations and disadvantages of autologous nerve transplantation have led to the development of tissue engineering. Various experimental approaches and novel technologies were initiated in the field of peripheral nerve injury repair to investigate potential solutions (3-5). Schwann cells (SCs), the major myelin-forming cells in the PNS, serve a vital role in nerve regeneration by secreting a variety of neurotrophic factors and forming the extracellular matrix (6). These characteristics of SCs mean that they have potential to aid in the repair of the central nervous system $(7,8)$. SC transplantation has become one of the best options for treating demyelinating diseases of the peripheral and central nervous systems (9). Neural stem cells (NSCs) are specific primitive nerve cells, which are present in the central nervous system and are able to differentiate into mature nerve cells, including neurons, astrocytes and oligodendrocytes, due to their multi-differentiation potential. NSCs may also be induced into SCs due to the low immunogenicity, NSCs have thus disproved the long-standing theory that neurons are unable to regenerate (10). NSCs may be expanded in vitro on a large scale and may be kept in long-term preservation. Furthermore, the characteristics they exhibit, including a multi-differentiation potential, high plasticity, ability to undergo transplant and low immunogenicity, permit them to be more appropriate than somatic cells for use in tissue engineering research $(11,12)$. It has been confirmed that transplanting NSCs into the nervous system promotes axonal regeneration and the formation of SC outer peripheral myelin (13). However, the base film and nerve growth factor are also required for peripheral nerve regeneration (14). When transplanted into the damaged site of the peripheral nerve, NSCs not only differentiate into SCs but also secrete certain favorable nerve growth factors $(15,16)$.

A number of neurotrophic factors secreted by NSCs also help to promote regeneration of damaged nerves $(17,18)$. Previous studies investigating the potential of NSCs to repair 
the peripheral nervous system (PNS) have provided more answers and the mechanisms of nerve damage repair are becoming increasingly clear. NSCs may promote cell regeneration, improve compatibility with the surrounding tissue transplantation site and due to low immunogenicity, they may limit or even attenuate the use of immunosuppressive drugs (19). One of the current challenges in neurobiology is to ensure that neural precursor cells differentiate into specific neuron types, so that they may be used for transplantation purposes in patients that have experienced neuron loss.

NSCs possess the capacity of self-renewal and multi-differentiation, allowing them to may differentiate into neurons, astrocytes and oligodendrocytes (10). When NSCs are cultured alone under differentiation cultivation conditions, they are prone to differentiate into glial cells; only a small fraction develop into neuron cells. Studies have investigated the co-culture of NSCs and SCs to repair both central and peripheral nerve injury (20-23); however, the specific mechanism of action is not fully understood.

The present study aimed to investigate the mechanisms of co-cultured NSCs and SCs in repairing peripheral nerve injury. The effects of neurotrophic factors and SCs on NSC survival and differentiation direction were also investigated.

\section{Materials and methods}

The animals and experimental protocols used in the present study were approved by the Ethics Committee of Shanghai General People's Hospital (Shanghai, China). All rats were provided standard mouse chow and water ad libitum, and housed under a $12 \mathrm{~h} \mathrm{light/dark} \mathrm{cycle} \mathrm{at} 24^{\circ} \mathrm{C}$ and $50 \%$ humidity.

Culture and identification of hippocampal NSCs of fetal rats. One female pathogen free Wistar rat (Shanghai SLAC Laboratory Animal Co., Ltd., Shanghai, China) 14-16 days pregnant for was anesthetized by abdominal administration of $10 \%$ chloral hydrate (Sigma-Aldrich; Merck KGaA, Darmstadt, Germany), $300 \mathrm{mg} / \mathrm{kg}$ body weight and fetuses removed under sterile conditions and sacrificed post-surgery by decapitation. The fetus brains were separated into two cerebral hemispheres and vascular membranes were peeled and removed under a dissecting microscope. Separated hippocampi were transferred into a 3.5-mm culture capsule filled with pre-cooled Dulbecco's modified Eagle's medium (DMEM)/F12 (1:1; Gibco; Thermo Fisher Scientific, Inc., Waltham, MA, USA). Cell suspension was created using TryPLE (pancreatic enzyme replacement fluid; Sigma-Aldrich; Merck KGaA, Darmstadt, Germany) for digestion in a water bath for $40 \mathrm{~min}$ at $37^{\circ} \mathrm{C}$, suspension solutions were centrifuged at $350 \mathrm{x} g$ for $5 \mathrm{~min}$ at $4^{\circ} \mathrm{C}$ and the supernatant was discarded. Complete medium was then used to resuspend and count. Cells were plated in T25 flasks at a density of $1 \times 10^{6}$ cells $/ \mathrm{ml}$ and cultured at $37^{\circ} \mathrm{C}$ in a $5 \% \mathrm{CO}_{2}$ incubator. Medium was changed once every two days and passage performed every seven days. Complete medium composition was as follows: DMEM/F12 (1:1) in serum-free medium, 2\% B27 (Invitrogen; Thermo Fisher Scientific, Inc.), $20 \mathrm{ng} / \mathrm{ml}$ epidermal growth factor (EGF; PeproTech, Inc., Rocky Hill, NJ, USA), $20 \mathrm{ng} / \mathrm{ml}$ basic fibroblast growth factor (bFGF; PeproTech, Inc.), L-glutamine (Gibco; Thermo Fisher Scientific, Inc.), $1 \%$ penicillin-streptomycin (Sigma-Aldrich;
Merck KgGA). Mouse anti-rat Nestin Monoclonal antibody (cat. no. 611826; 1:500; BD Pharmingen, San Diego, CA, USA) immunofluorescence staining was used to identify NSCs.

Primary culture and subculture method and identification of newborn rat SCs. A total of 10 newborn Wistar male rats (Shanghai SLAC Laboratory Animal Co., Ltd.) were purchased at 3-5 days old (10-12 g). All rats were provided standard mouse chow and water ad libitum, and housed under a $12 \mathrm{~h} \mathrm{light/dark}$ cycle at $24^{\circ} \mathrm{C}, 50 \%$ humidity. Rats were decapitated, the skin was disinfected with $75 \%$ alcohol and then the bilateral sciatic nerve was dissected under sterile conditions by removing the epineurium and connective tissue under a dissecting microscope. Nerves were then cut into $1 \mathrm{~mm}^{3}$ fragments with ophthalmic scissors. Nerve fragments were then mixed with digestion solution that contained $0.2 \%$ NB4 collagenase (Invitrogen; Thermo Fisher Scientific, Inc.) and $0.2 \%$ Dispase II (neutral enzyme; Roche Applied Science, Penzberg, Germany) at a ratio of 2:1. The solutions were put on a shaker at $37^{\circ} \mathrm{C}$ to digest for $45 \mathrm{~min}$. During the digestion period solutions were agitated twice. At the end of digestion, the well-digested single-cell suspension was centrifuged at $524 \mathrm{x} g$ for $5 \mathrm{~min}$ at $4^{\circ} \mathrm{C}$ and the supernatant was discarded. Cells were resuspended and counted with an inverted light microscope (CKX41; Olympus Corporation, Tokyo, Japan) in SC medium containing DMEM/low glucose, $10 \%$ fetal bovine serum (FBS; Hyclone; GE Healthcare Life Sciences, Logan, UT, USA), $20 \mathrm{ng} / \mathrm{ml} \mathrm{bFGF,} 20 \mathrm{ng} / \mathrm{ml}$ Heregulin (Sigma-Aldrich; Merck KGaA), $4 \mu \mathrm{M}$ Forskolin (Sigma-Aldrich; Merck KGaA) and $1 \%$ penicillin-streptomycin (Sigma-Aldrich; Merck $\mathrm{KGaA}$ ). Cells were subsequently planted in a $10-\mathrm{cm}$ culture capsule at a density of $1 \times 10^{6} / \mathrm{ml}$ and cultured at $37^{\circ} \mathrm{C}$ in a $5 \%$ $\mathrm{CO}_{2}$ incubator. Passage was performed two days later. At the time of passage, well-incubated $0.2 \%$ Dispase II was selected and digested for $10-15 \mathrm{~min}$ at $37^{\circ} \mathrm{C}$ until the majority of SCs were digested. Following two passages, the purity of SCs was $>98 \%$. Rabbit anti-rat S100 (mo76101; 1:100; Dako; Agilent Technologies, Inc., Santa Clara, CA, USA) was used for immunofluorescence staining of SCs. Blocking was performed for $30 \mathrm{~min}$ at room temperature with $5 \%$ bovine serum albumin (Beyotime Institute of Biotechnology, Haimen, China) before incubation overnight with $\mathrm{S} 100$ (as above) at $4^{\circ} \mathrm{C}$ in the dark. Cells were subsequently incubated with goat anti-rabbit- fluorescein isothiocyanate 488 secary antibody (sc-2704; 1:500; Santa Cruz Biotechnology, Inc.) at $37^{\circ} \mathrm{C}$ for $45 \mathrm{~min}$ in the dark. Cells were observed under a laser scanning confocal microscope (C2+; Nikon Corporation, Tokyo, Japan) and analyzed using NIS-elements AR software (V4200; Nikon Corporation).

Detection and identification of NSCs co-cultured with SCs. Cells were divided into three groups: i) SC group of P2-4 generation, ii) NSC group later than P2 generation, and iii) SC + NSC (SCs:NSCs 1:1) group. Cells were cultured for 7 days at $37^{\circ} \mathrm{C}$, in an atmosphere contatining $5 \% \mathrm{CO}_{2}$ (HERA cell 150i; Thermo Fisher Scientific, Inc.). Morphological changes were observed under an inverted phase contrast microscope and documented on a daily basis; supernatants were removed and analyzed on days 1, 3, 5 and 7. Secretion of brain-derived neurotrophic factor (BDNF) and glial-derived neurotrophic factor (GDNF) was assessed using an ELISA 
Heregulin- $\beta$-1 assay (ELISA assay kit, cat. no. EK0308-1 and EK0363-1, rat BDNF, GDNF from Syd Labs, Inc. Natick, MA, USA) for all three groups, followed by a 3-(4,5-dimethylthiazol-2-yl)-2,5-diphenyltetrazolium bromide (MTT) cell viability assay (Sigma-Aldrich; Merck KGaA) to confirm cell survival in all three groups. Differentiation medium included DMEM/F12 (1:1), 2\% B27, 20 ng/ml bFGF, 20 ng/ml EGF and $1 \%$ FBS. Markers for cell type identification were rat anti-rabbit S100 protein (mo76101; 1:100; Dako; Agilent Technologies, Inc.) for SC labeling, goat anti-mouse glial fibrillary acidic protein (GFAP) monoclonal antibody (ab27952; 1:500; Abcam, Cambridge, UK) for astrocyte labeling and rabbit anti-human microtubule associated protein (Map2) polyclonal antibody for neuron labeling (sc-20978; 1:500; Santa Cruz Biotechnology, Inc., Dallas TX, USA).

Directional differentiation of NSCs. Culture was subdivided into three subgroups: SCs, NSCs and co-culture groups. All groups were seeded in the differentiation culture media under differentiation medium. Four target genes, BDNF, GDNF, Map2, and glial fibrillary acidic protein (GFAP) were selected. Map2 is the specific marker for neurons, while GFAP is the marker for astrocytes. BDNF and GDNF are two primary neurotrophic factors secreted primarily by SCs. The cells were seeded for 7 days and culture media were changed every other day. On day 7 following seeding, gene expression was measured by reverse transcription-quantitative polymerase chain reaction (RT-qPCR) for these four target genes within different groups under appropriate serum concentrations using the QTaq ${ }^{\mathrm{TM}}$ One-Step RT-qPCR SYBR ${ }^{\circledR}$ kit, (Takara Bio, Inc., Otsu, Japan).

In order to extract RNA, cells were harvested $\left(1 \times 10^{7}\right.$ cells $/ 10 \mathrm{~cm}$ plate) and $1 \mathrm{ml} \mathrm{TRIzol}{ }^{\mathrm{TM}}$ (Invitrogen; Thermo Fisher Scientific, Inc.) was added to dissociated cells and then distributed to tubes following complete homogenization. The tube was inverted 10 times and allowed to stand for $5 \mathrm{~min}$ at room temperature.

Chloroform was added (one-fifth of the total volume), the tube was inverted 10 times and was allowed to stand for $5 \mathrm{~min}$ at room temperature. The resultant solution was centrifuged for $15 \mathrm{~min}$ at $12,000 \times \mathrm{g}$ and $4^{\circ} \mathrm{C}$, and the upper aqueous phase $(400 \mu \mathrm{l})$ was removed to a new tube. An equal volume of isopropyl alcohol $(400 \mu \mathrm{l})$ was added, incubated for $10 \mathrm{~min}$ following mixing and centrifuged for $10 \mathrm{~min}$ at $12,000 \mathrm{x} \mathrm{g}$ and $4^{\circ} \mathrm{C}$. The supernatant was removed and replaced with $1 \mathrm{ml}$ cold $75 \%$ alcohol, dissolved with diethyl pyrocarbonate (DEPC; ST036; Beyotime Institute of Biotechnology). The resultant solution was centrifuged for $5 \mathrm{~min}$ at 7,500 $\mathrm{x} \mathrm{g}$ and $4^{\circ} \mathrm{C}$. The supernatant was discarded and the remaining pellet was dried for 5-10 min. The precipitation was dissolved in $20 \mu \mathrm{l}$ DEPC. Total RNA was quantified using a NanoDrop 2000c Spectrophotometer (Thermo Fisher Scientific, Inc.). The RNA quality was evaluated through 15-20 min 1.5\% agarose gel electrophoresis using $5 \mu \mathrm{l}$ PCR product and $1 \mu \mathrm{l}$ bromophenol blue, followed by spectrophotometry (MJ Research; Bio-Rad Laboratories, Inc., Hercules, CA, USA) to determine (OD) 260/OD280. The reverse transcription reaction was made up as follows: $1 \mu \mathrm{l}$ RNA, $2 \mu \mathrm{l}$ mix (Takara Bio Inc.) and $7 \mu \mathrm{l}$ DEPC, with a total volume of $10 \mu \mathrm{l}$. The samples were then incubated at $37^{\circ} \mathrm{C}$ for $15 \mathrm{~min}$ followed by $85^{\circ} \mathrm{C}$ for $5 \mathrm{sec}$.
Samples were stored at $4^{\circ} \mathrm{C}$ for use in future experiments. A total of $20 \mu \mathrm{l}$ reaction product was used for each PCR reaction, consisting of $10 \mu 1 \mathrm{SYBR}$ green mix, $1 \mu \mathrm{l}$ forward primer, $1 \mu \mathrm{l}$ reverse primer, $1 \mu \mathrm{l}$ cDNA and $7 \mu \mathrm{l}$ DEPC. For the PCR reaction, $\beta$-actin was used as a control. The PCR reaction was completed as follows: $95^{\circ} \mathrm{C}$ for 2 min to pre-denature samples, $95^{\circ} \mathrm{C}$ for $10 \mathrm{sec}$ to denature, $60^{\circ} \mathrm{C}$ for $30 \mathrm{sec}$ for 40 cycles and $72^{\circ} \mathrm{C}$ for $30 \mathrm{sec}$. PCR was completed in a CFX-96 thermocycler (Bio-Rad Laboratories, Inc.). Primers were synthesized for the specific target genes as follows: GDNF, forward: 5'-CTGACT TGGGTTTGGGCTAC-3' and reverse 5'-CCTGGCCTACCT TGTCACTT-3', BDNF forward: 5'-GGGACCTCGGAACTC AAC-3' and reverse: 5'-TGTATCTGCCTGGGACTG-3', Map2 forward: 5'-GACCACCAGGTCAGAACCAAT-3' and reverse 5'-TGGTGTCCTGGGATAGCTCG-3' and GFAP forward: 5'-ATGGAGCTCAATGACCGCTT-3' and reverse: 5'-ATC TTGGAGCTTCTGCCTCAG-3'.

Statistical analysis. The transcription profile was obtained from three independent experiments performed in duplicate. SPSS version 19.0 software was used to analyze data (IBM SPSS, Armonk, NY, USA). Data are presented as mean \pm standard deviation. One-way analysis of variance was used for statistical analysis across all groups. $\mathrm{P}<0.05$ was considered to represent a statistically significant difference.

\section{Results}

Morphological results of NSC differentiation. The majority of the NSCs in the co-cultured group differentiated into neurons, with a small population that differentiated into astrocytes. Neuron cell bodies were translucent with a slender shape with multiple processes, indicating that the cells were in good shape (Fig. 1A). Neurons were also present in the NSC group, but there were a smaller number of cells overall and the state of the neurons was clearly not as healthy as those grown in the co-cultured group (Fig. 1B). For the SC group, the morphology of the cells was the same as those cultured in SC medium and had no differentiation trend (Fig. 1C). Following immunofluorescence staining, nerve ball cells in the co-cultured group exhibited a gradual spread and differentiated into neurons with positive Map2 staining (Fig. 2A), while in the NSC group, a small number of cells differentiated into neurons, and a large proportion of cells differentiated into astrocytes (Fig. 2B).

Survival cells detected by MTT colorimetry. The survival rate in the SC group was significantly higher than the NSC group $(\mathrm{P}<0.05)$, but demonstrated no significant difference compared with the co-cultured group at days 1 and 7 . However, the survival rate of the co-culture group was significantly higher than the other groups at days 3,5 and $10(\mathrm{P}<0.01)$. The cell survival rate of the co-culture group was significantly higher compared with NSC groups at all points $(\mathrm{P}<0.05$; Fig. 3$)$.

Secretion of BDNF and GDNF. The supernatant of the three groups were assessed using an ELISA assay. Levels of neurotrophic factors secreted by cells varied in each group on different days. For BDNF, on day 1, there was no statistically significant difference between the three groups, while on days 3 and 5, the amount of BDNF in the co-culture group and 

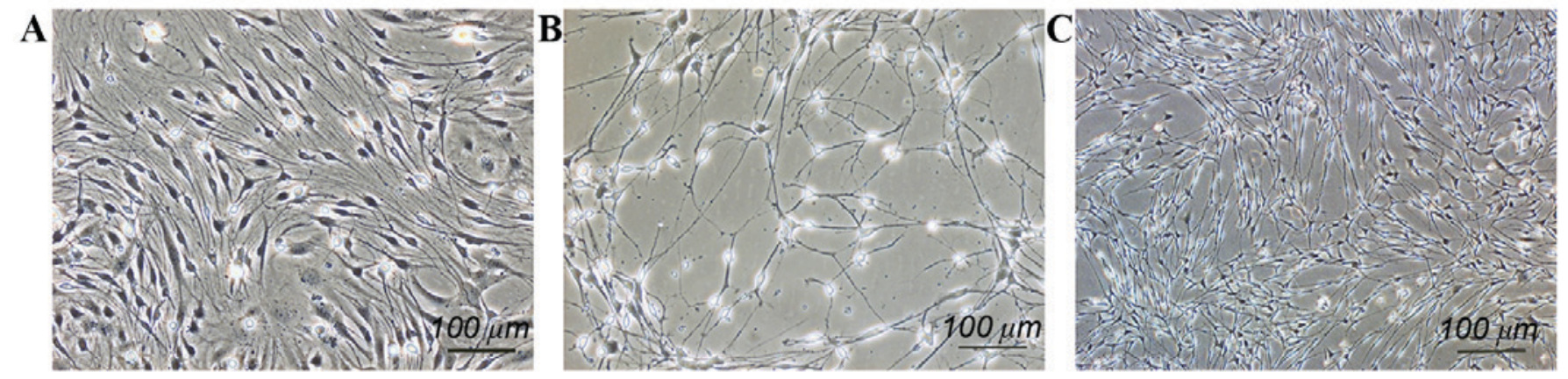

Figure 1. Cell morphology under phase contrast microscopy. (A) Co-culture group, neuron cell bodies were translucent with a slender shape and multiple processes, typical of neurons. (B) neural stem cells group, a smaller amount of neuron cells were present, and the state of neurons was not as healthy as the co-culture group. (C) In the Schwann cell group, cell morphology was the same as culturing in Schwann cell culture medium and had no differentiation trend. Scale bar, $100 \mu \mathrm{m}$.
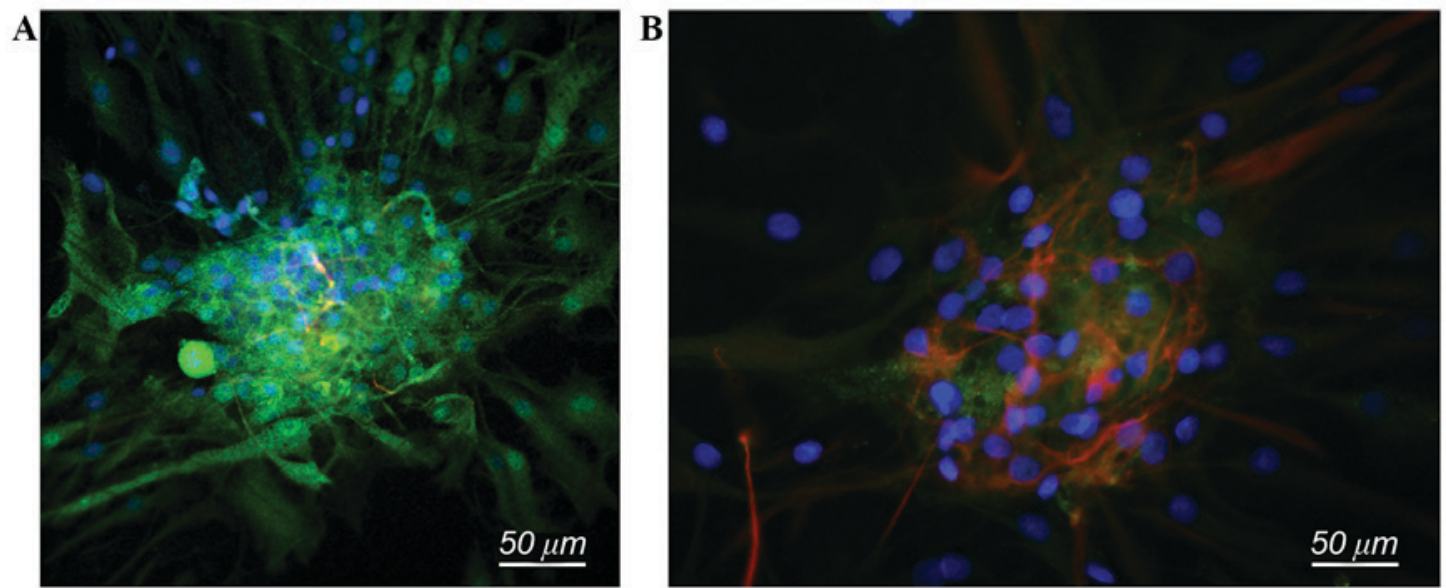

Figure 2. Immunofluorescence staining of co-cultured and NSC groups. (A) NSC neurospheres in the co-cultured group gradually differentiate into neurons with Map2-positive immunofluorescence staining (green), cell nuclei stained by DAPI (blue). (B) NSC group, a small number of cells differentiate into neurons, Map2-positive (green), while a large proportion of cells differentiate into astrocytes, glial fibrillary acidic protein positive (red), cell nuclei stained by DAPI (blue). Scale bar, $50 \mu \mathrm{m}$. NSC, neural stem cells; Map2, microtubule associated protein; DAPI, 4',6-diamidino-2-phenylindole.

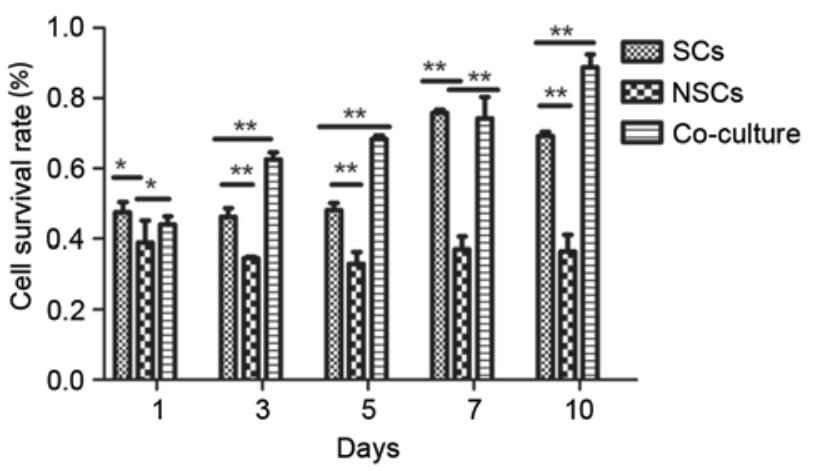

Figure 3. Following MTT assay, the survival rate in the SC group was significantly higher than the NSC group, but demonstrated no significant difference with the co-cultured group at days 1 and 7 . However, the survival rate of the co-culture group was significantly higher than the other groups at days 3 , 5 and 10 . The cell survival rate of the co-culture group was significantly improved compared with the NSC group. ${ }^{*} \mathrm{P}<0.05,{ }^{* *} \mathrm{P}<0.01$. SC, Schwann cells; NSC, neural stem cells.

SCs was significantly higher than NSCs $(\mathrm{P}<0.05$; Fig. 4A). On day 7, the amount of BDNF secreted by the co-culture group and SCs was significantly higher than that secreted by NSCs
$(\mathrm{P}<0.05)$, and that in the co-culture group was significantly higher than the SC group $(\mathrm{P}<0.05$; Fig. 4A). For GDNF, on day 1 , the amount in the co-culture group was significantly higher than both NSC and SC groups $(\mathrm{P}<0.01)$, but there was no difference between NSC and SC groups (Fig. 4B). On days 3, 5 and 7 , the amount in the co-culture group was significantly higher than the SC group $(\mathrm{P}<0.01)$, and that in the SC group was higher than the NSC group $(\mathrm{P}<0.01$; Fig. 4B). Therefore, the overall trend was as follows: The co-culture group had a higher expression of BDNF and GDNF than the SC group, which had a higher expression than the NSC group (Fig. 4).

mRNA expression of BDNF, GDNF, Map2, and GFAP. Following 7 days seeding in the culture media, the mRNA expression of four different target genes, BDNF, GDNF, Map2, and GFAP was measured by RT-qPCR. The results demonstrated that BDNF and GDNF gene expression in the co-culture group was significantly higher than in the SC group, while the SCs exhibited significantly higher expression of BDNF and GDNF than the NSC group (all $\mathrm{P}<0.01$; Fig. 5). Secondly, the gene expression of Map2 in the co-culture group was significantly higher than both NSC and SC groups $(\mathrm{P}<0.01)$, 

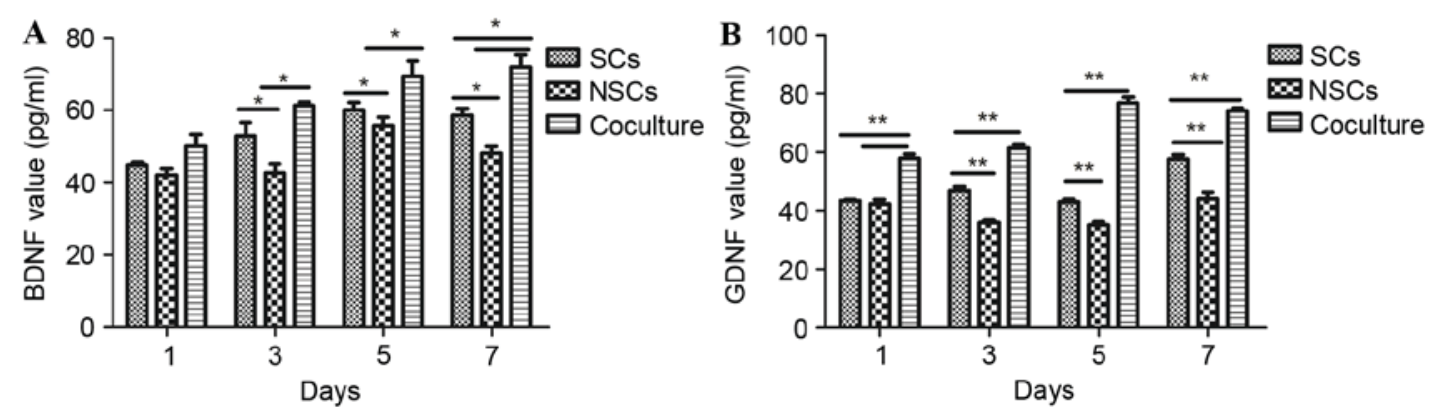

Figure 4. ELISA assay of cell secretion. (A) BDNF and (B) GDNF expression in supernatant of the three groups. The overall trend is that the co-culture group has a higher expression than the Schwann cell group, which has a higher expression than the neural stem cell group. ${ }^{*} \mathrm{P}<0.05,{ }^{* *} \mathrm{P}<0.01$. BDNF, brain-derived neurotrophic factor; GDNF, glial cell-derived neurotrophic factor; NSC, neural stem cells; SC, Schwann cells.
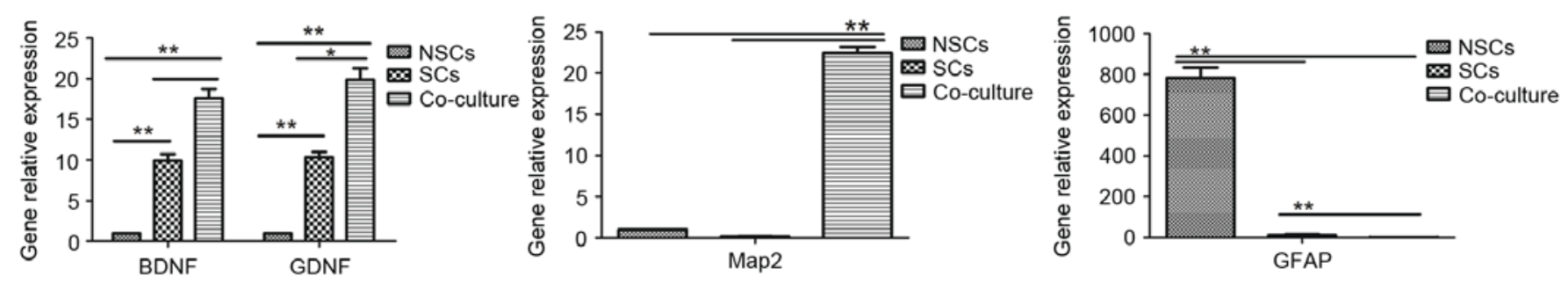

Figure 5. Comparison of gene expression for BDNF, GDNF, Map2 and GFAP in all three groups. ${ }^{*} \mathrm{P}<0.05,{ }^{* *} \mathrm{P}<0.01$. BDNF, brain-derived neurotrophic factor; GDNF, glial cell-derived neurotrophic factor; GFAP, glial fibrillary acidic protein; NSC, neural stem cells; SC, Schwann cells; Map2, microtubule associated protein 2 .

while there was no significant difference between NSC and SC groups (P>0.05; Fig. 5). For GFAP gene expression, the NSC group exhibited the highest expression, followed by SCs and then the co-culture group; there was a significant difference between each group (each $\mathrm{P}<0.01$; Fig. 5). The results suggest that co-culture of NSCs and SCs promotes NSCs to differentiate into neurons, while in independent cultures, NSCs are promoted to differentiate into astrocytes.

\section{Discussion}

When damage occurs in the PNS, neuronal degeneration stimulates a series of reactions (24). When the distal end of the extruded or severed axons undergo Wallerian degeneration, axons and myelin disintegrate. The resulting disintegrating matter is cleared by macrophages and SCs (25). The SCs differentiate and regain division and proliferation functions to regenerate new cells that form the Bünger band, providing a suitable microenvironment for axonal regeneration and surrounding the newborn axons to form the myelin sheath (26). SCs are also able to secrete cell adhesion molecules, such as laminin and fibronectin, which function in a similar way to the extracellular matrix, thus supporting axonal growth (27).

NSCs possess a capacity for self-renewal and multi-differentiation. The current study demonstrated that following co-culture with SCs, NSCs are induced to differentiate into neurons. Furthermore, various neurotrophic factors secreted by SCs may also promote bridging between cells, supporting the survival of neurons $(28,29)$. NSCs grafted to injured zones of peripheral nerve tissue differentiate into motor neurons, the axons of which may reach the muscle tissue. NSCs thus serve a role in delaying muscle atrophy prior to contact between differentiated neurons and establishment of denervated muscles $(30,31)$.

The view that neurotrophic factors promote nerve repair is well supported $(32,33)$. BDNF is the second factor to have been identified in the neurotrophic factor family, which has 54\% sequence homology to nerve growth factor (NGF) and serves a variety of functions in the nervous system $(32,33)$. BDNF is a very important neurotrophic factor for motor neurons, as it may affect the expression of cholinergic genes and promote the survival of cultured cells (28). GDNF closely links with its corresponding receptor and transforming growth factor family, promoting motor and sensory neuron survival (34-36). It may also enhance the formation of myelin by facilitating the migration of SCs (37).

In the present study, more cells differentiated into neurons when NSCs were co-cultured with SCs, and these cells possessed good morphological features including bright rounded spots with two or three apophyses (Fig. 1). Using ELISA to assess secretion of the two factors BDNF and GDNF, it was confirmed that under co-culture conditions, the secretion of various neurotrophic factors was higher $(\mathrm{P}<0.05)$ than under individually cultured conditions, indicating that co-culture produced an improved nerve growth microenvironment. The MTT assay demonstrated that cell survival in the co-culture group is higher than in the other two groups, which is in accordance with neurotrophic factor levels. During the experiment, it was also observed that in the co-cultured group, not only were more neurons formed, but the cell morphology of SCs was different compared with the cultured alone group, and SC volume was larger with more stout processes observed. Levels of nerve growth factors confirmed that SCs promote NSC growth and induce 
differentiation of NSCs into neurons. However, the production of NSCs during proliferation and differentiation may also promote the growth of SCs. The present study assessed levels of the two neurotrophic factors, BDNF and GDNF. However, other factors such as nerve growth factor and ciliary neurotrophic factor may also be involved in the differentiation of NSCs. The specific mechanisms of action remain to be confirmed in future studies.

In conclusion, the current study confirmed that co-culturing SCs and NSCs in vitro improved the nerve regeneration microenvironment. Positive changes to cell morphology by interaction of the two cell types was also observed. However, nerve function recovery is still a huge challenge in peripheral nerve repair; the present study only verified the merits of nerve gap bridging and increasing secretion of nerve growth factors. The effect of co-culture of SCs and NSCs on regeneration and functional recovery of damaged peripheral nerve may be verified through in vivo animal experiments in the future.

\section{Acknowledgments}

The current study was supported by grants from the Natural Science Foundation of China (Beijing, China; no. 81170925) and K.C.Wong Education Foundation of Shanghai Jiao Tong University School of Medicine (Shanghai, China).

\section{References}

1. Lee SK and Wolfe SW: Peripheral nerve injury and repair. J Am Acad Orthop Sur 8: 243-252, 2000.

2. Siemionow M, Duggan W, Brzezicki G, Klimczak A, Grykien C, Gatherwright J and Nair D: Peripheral nerve defect repair with epineural tubes supported with bone marrow stromal cells: A preliminary report. Ann Plast Surg 67: 73-84, 2011.

3. Lloyd BM, Luginbuhl RD, Brenner MJ, Rocque BG, Tung TH, Myckatyn TM, Hunter DA, Mackinnon SE and Borschel GH: Use of motor nerve material in peripheral nerve repair with conduits. Microsurgery 27: 138-145, 2007.

4. Lubiatowski P, Unsal FM, Nair D, Ozer K and Siemionow M: The epineural sleeve technique for nerve graft reconstruction enhances nerve recovery. Microsurgery 28: 160-167, 2008.

5. Scharpf J, Meirer R, Zielinski M, Unsal M, Ramineni P, Nair D and Siemionow M: A novel technique for peripheral nerve repair. Laryngoscope 113: 95-101, 2003.

6. Kanno H, Pressman Y, Moody A, Berg R, Muir EM, Rogers JH, Ozawa H, Itoi E, Pearse DD and Bunge MB: Combination of engineered Schwann cell grafts to secrete neurotrophin and chondroitinase promotes axonal regeneration and locomotion after spinal cord injury. J Neurosci 34: 1838-1855, 2014.

7. Olson HE, Rooney GE, Gross L, Nesbitt JJ, Galvin KE, Knight A, Chen B, Yaszemski MJ and Windebank AJ: Neural stem cell- and Schwann cell-loaded biodegradable polymer scaffolds support axonal regeneration in the transected spinal cord. Tissue Eng Part A 15: 1797-1805, 2009.

8. Bunge RP: The role of the Schwann cell in trophic support and regeneration. J Neurol 242 (1 Suppl 1): S19-S21, 1994.

9. Kanno H, Pressman Y, Moody A, Berg R, Muir EM, Rogers JH, Ozawa H, Itoi E, Pearse DD and Bunge MB: Combination of engineered Schwann cell grafts to secrete neurotrophin and chondroitinase promotes axonal regeneration and locomotion after spinal cord injury. J Neurosci 34: 1838-1855, 2014.

10. Parker MA, Anderson JK, Corliss DA, Abraria VE, Sidman RL, Park KI, Teng YD, Cotanche DA and Snyder EY: Expression profile of an operationally-defined neural stem cell clone. Exp Neurol 194: 320-332, 2005.

11. Alessandri G, Emanueli C and Madeddu P: Genetically engineered stem cell therapy for tissue regeneration. Ann N Y Acad Sci 15: 271-284, 2004.

12. Goldman SA and Sim F: Neural progenitor cells of the adult brain. Novartis Found Symp 265: 66-80, 82-97, 2005.
13. Blakemore WF: The case for a central nervous system (CNS) origin for the Schwann cells that remyelinate CNS axons following concurrent loss of oligodendrocytes and astrocytes. Neuropathol Appl Neurobiol 31: 1-10, 2005.

14. Georgiou M, Bunting SC, Davies HA, Loughlin AJ, Golding JP and Phillips JB: Engineered neural tissue for peripheral nerve repair. Biomaterials 34: 7335-7343, 2013.

15. Dong MM and Yi TH: Stem cell and peripheral nerve injury and repair. Facial Plast Surg 26: 421-427, 2010.

16. Mirsky R, Jessen KR, Brennan A, Parkinson D, Dong Z, Meier C, Parmantier E and Lawson D: Schwann cells as regulators of nerve development. J Physiol Paris 96: 17-24, 2002.

17. Rodriguez AM, Pisani D, Dechesne CA, Turc-Carel C, Kurzenne JY, Wdziekonski B, Villageois A, Bagnis C, Breittmayer JP, Groux H, et al: Transplantation of a multipotent cell population from human adipose tissue induces dystrophin expression in the immunocompetent mdx mouse. J Exp Med 201: 1397-1405, 2005.

18. Mosahebi A, Woodward B, Wiberg M, Martin R and Terenghi G: Retroviral labeling of Schwann cells: In vitro characterization and in vivo transplantation to improve peripheral nerve regeneration. Glia 34: 8-17, 2001.

19. MacDonald SC, Fleetwood IG, Hochman S, Dodd JG, Cheng GK, Jordan LM and Brownstone RM: Functional motor neurons differentiating from mouse multipotent spinal cord precursor cells in culture and after transplantation into transected sciatic nerve. J Neurosurg 98: 1094-1103, 2003.

20. Xia L, Wan H, Hao SY, Li DZ, Chen G, Gao CC, Li JH, Yang F, Wang SG and Liu S: Co-transplantation of neural stem cells and Schwann cells within poly (L-lactic-co-glycolic acid) scaffolds facilitates axonal regeneration in hemisected rat spinal cord. Chin Med J (Engl) 126: 909-917, 2013.

21. Zhang X, Zeng Y, Zhang W, Wang J, Wu J and Li J: Co-transplantation of neural stem cells and NT-3-overexpressing Schwann cells in transected spinal cord. J Neurotrauma 24: 1863-1877, 2007.

22. Zeng YS, Ding Y, Wu LZ, Guo JS, Li HB, Wong WM and Wu WT: Co-transplantation of schwann cells promotes the survival and differentiation of neural stem cells transplanted into the injured spinal cord. Dev Neurosci 27: 20-26, 2005.

23. Xu L, Zhou S, Feng GY, Zhang LP, Zhao DM, Sun Y, Liu Q and Huang F: Neural stem cells enhance nerve regeneration after sciatic nerve injury in rats. Mol Neurobiol 46: 265-274, 2012.

24. Fex Svennigsen A and Dahlin LB: Repair of the Peripheral Nerve-Remyelination that Works. Behav Brain Sci 3: 1182-1197, 2013.

25. Mikami Y, Okano H, Sakaguchi M, Nakamura M, Shimazaki T, Okano HJ, Kawakami Y, Toyama Y and Toda M: Implantation of dendritic cells in injured adult spinal cord results in activation of endogenous neural stem/progenitor cells leading to de novo neurogenesis and functional recovery. J Neurosci Res 76: 453-465, 2004.

26. Evans GR: Peripheral nerve injury: A review and approach to tissue engineered constructs. Anat Rec 263: 396-404, 2001.

27. Madduri S and Gander B: Schwann cell delivery of neurotrophic factors for peripheral nerve regeneration. J Peripher Nerv Syst 15: 93-103, 2010.

28. An YH, Wan H, Zhang ZS, Wang HY, Gao ZX, Sun MZ and Wang ZC: Effect of rat Schwann cell secretion on proliferation and differentiation of human neural stem cells. Biomed Environ Sci 16: 90-94, 2003.

29. Niapour A, Karamali F, Nemati S, Taghipour Z, Mardani M, Nasr-Esfahani $\mathrm{MH}$ and Baharvand $\mathrm{H}$ : Cotransplantation of human embryonic stem cell-derived neural progenitors and schwann cells in a rat spinal cord contusion injury model elicits a distinct neurogenesis and functional recovery. Cell Transplant 21: 827-843, 2012.

30. Heath CA: Cells for tissue engineering. Trends Biotechnol 18: 17-19, 2000.

31. Shen Y, Xu J, Xu W, Xu L, Lu J and Gu Y: Experimental study on neural stem cell transplantation delaying denervated muscle atrophy. Zhongguo Xiu Fu Chong Jian Wai Ke Za Zhi 22: 1051-1055, 2008 (In Chinese).

32. Leibrock J, Lottspeich F, Hohn A, Hofer M, Hengerer B, Masiakowski P, Thoenen $\mathrm{H}$ and Barde YA: Molecular cloning and expression of brain-derived neurotrophic factor. Nature 341: 149-152, 1989.

33. Squinto SP, Stitt TN, Aldrich TH, Davis S, Bianco SM, Radziejewski C, Glass DJ, Masiakowski P, Furth ME and Valenzuela DM: trkB encodes a functional receptor for brain-derived neurotrophic factor and neurotrophin-3 but not nerve growth factor. Cell 65: 885-893, 1991. 
34. Henderson CE, Camu W, Mettling C, Gouin A, Poulsen K, Karihaloo M, Rullamas J, Evans T, McMahon SB and Armanini MP: Neurotrophins promote motor neuron survival and are present in embryonic limb bud. Nature 363: 266-270, 1993.

35. Matheson CR, Carnahan J, Urich JL, Bocangel D, Zhang TJ and Yan Q: Glial cell line-derived neurotrophic factor (GDNF) is a neurotrophic factor for sensory neurons: Comparison with the effects of the neurotrophins. J Neurobiol 32: 22-32, 1997.
36. Nagano M and Suzuki H: Quantitative analyses of expression of GDNF and neurotrophins during postnatal development in rat skeletal muscles. Neurosci Res 45: 391-399, 2003.

37. Iwase T, Jung CG, Bae H, Zhang M and Soliven B: Glial cell line-derived neurotrophic factor-induced signaling in Schwann cells. J Neurochem 94: 1488-1499, 2005. 